\title{
Rectal spirochaetosis in homosexual men: characterisation of the organism and pathophysiology
}

\author{
C COOPER, $*$ D W K COTTON, $\uparrow$ M J HUDSON, $\ddagger$ N KIRKHAM, $\uparrow$ AND F E W WILMOTT* \\ From the Departements of ${ }^{*}$ Genitourinary Medicine and †Histopathology, Royal South Hants Hospital, and \\ Southampton General Hospital, Southampton, Hampshire, and the $\ddagger$ Public Health Laboratory Service Centre for \\ Applied Microbiology and Research, Porton Down, Salisbury, Wiltshire
}

SUMMARY Microbiological and electron microscopy studies were carried out on rectal biopsy specimens and faecal samples from eight practising male homosexuals and five heterosexual controls. Rectal spirochaetosis was present in five of the eight homosexual men. The organism was cultured and morphologically identified as a large anaerobic host associated treponeme. The degrees of infestation and depletion of microvilli were also measured. The results are discussed in relation to the possible clinical importance of rectal spirochaetosis.

\section{Introduction}

Infestation of the human gastrointestinal tract by spirochaetes is a well recognised phenomenon, though doubt is still expressed as to its pathological importance. ${ }^{1}$ In early studies the diagnosis was made histologically, but two groups of workers have recently reported the isolation and culture of anaerobic treponemes from the faeces and rectal biopsy specimens of affected patients. ${ }^{2}$. $^{2}$

The prevalence of rectal spirochaetosis (as judged histologically and by electron microscopy) varies considerably in hospital patients who have undergone rectal biopsy, with a range from $1.9 \%{ }^{4}$ to $6.9 \%{ }^{5}$ reported. A much higher prevalence $(36 \%)$ has been described in homosexual men, ${ }^{6}$ however, and the condition is sometimes associated with diarrhoea, purulent rectal discharge, and pain on defaecation, ${ }^{78}$ but a histological inflammatory response is not detectable in rectal biopsy specimens from these men.

In the study published here we aimed to investigate this condition in detail in a group of homosexual men in an attempt to culture the organism, assess its importance, and elucidate the pathogenesis of the condition with particular reference to the phenomenon of symptomatology without histologically detectable inflammation.

Address for reprints: Dr C Cooper, Department of Genitourinary Medicine, Royal South Hants Hospital, Graham Road, Southampton, Hampshire SO9 4PE

Accepted for publication 14 August 1985

\section{Patients and Methods}

\section{PATIENTS}

We carried out rectal biopsies on eight homosexual men, aged 24 to 45 (mean 32) years, who presented to the department of genitourinary medicine at the Royal South Hants Hospital. All were engaged in regular active and passive anal intercourse, and three had symptoms suggestive of proctitis (diarrhoea and pain on defaecation in two, and purulent rectal discharge, diarrhoea, and pain on defaecation in the third). Screening for sexually transmitted pathogens (Neisseria gonorrhoeae, Treponema pallidum, herpes simplex virus, and Candida spp) by Gram stain and culture of rectal smears, and for other gastrointestinal pathogens (Salmonella spp, Shigella spp, and Campylobacter spp) by stool culture, gave negative results in all cases. Informed consent was obtained from all the patients, and the study was approved by the district ethical committee. We obtained control biopsy specimens from five men in the same age range who were undergoing rectal biopsy for the exclusion of inflammatory bowel disease. In all of them stool culture and radiological studies of the large bowel gave negative results, and no abnormality could be detected on sigmoidoscopy or histology.

We obtained three specimens from each patient; the first was immediately fixed in $10 \%$ phosphate buffered formaldehyde and embedded in paraffin. Sections were made and stained with haematoxylin and eosin. The second was transported in $2.5 \%$ glutaraldehyde 
for transmission electron microscopy, and the third was transported in cryoprotective medium at $-40^{\circ} \mathrm{C}$ to an anaerobic chamber, where all subsequent culture work was done.

\section{ELECTRON MICROSCOPY}

\section{Method for scanning electron microscopy}

Specimens were fixed in neutral buffered formalin for 24 hours and stored in cacodylate and sucrose buffer for up to five days at $4^{\circ} \mathrm{C}$. They were post fixed for two to three hours in $2 \%$ osmium tetroxide in veronal acetate buffer and dehydrated in graded acetone solutions. They were critical point dried from acetone in a Polaron E300 critical point drier using liquid carbon dioxide as the exchange medium. The specimens were mounted on stubs using Leit-C conductive carbon cement and coated with goldpalladium to a thickness of about $20 \mathrm{~nm}$ in a Polaron E5100 sputter coater. They were examined in a JEOL JSM-85 scanning electron microscope at $25 \mathrm{kv}$ using a working distance of $39 \mathrm{~mm}$.

\section{Method for transmission electron microscopy}

Small blocks of tissue were fixed in neutral buffered formalin for 24 hours and stored in cacodylate and sucrose buffer at $4^{\circ} \mathrm{C}$. They were post fixed for two hours in $2 \%$ osmium tetroxide in veronal acetate and block stained with $1.5 \%$ uranyl acetate for 30 minutes. The blocks were dehydrated in graded ethanol solutions, then passed through equal amounts of Histosol and resin, and finally into $100 \%$ Spurr's low viscosity resin for 24 hours. They were then transferred to fresh resin in capsules and polymerised in an oven at $60^{\circ} \mathrm{C}$ for 16 hours. After being trimmed, $0.5 \mu \mathrm{m}$ thick plastic sections were cut and stained with toluidine blue. Ultrathin (about $70 \mathrm{~nm}$ ) sections were cut from selected areas, stained with Reynold's lead citrate, and examined on a Phillips 201 or 300 electron microscope.

\section{Counting microvilli and organisms}

On examining each specimen by transmission electron microscopy, we counted the number of epithelial cell microvilli per cell profile, using eight contiguous epithelial cells. Epithelial cell boundaries were defined by the presence of tight juctions. In patients with spirochaetosis, we also counted the number of spirochaetes attached to each epithelial cell. We assessed variation between observers by using two observers (CC and DWKC) to perform counts on each field separately.

\section{BACTERIOLOGICAL CULTURE METHODS}

Faecal samples or mucosal biopsy specimens in cryoprotective broth were thawed in an anaerobic chamber (containing 10\% hydrogen and $10 \%$ carbon dioxide in nitrogen) for subsequent cultivation. ${ }^{9}$ Faecal suspensions and mucosal macerates and washings were plated directly on to non-selective agar medium ${ }^{9}$ or the same medium made selective by adding spectinomycin hydrochloride $400 \mathrm{mg} / 1$ and polymyxin B sulphate $5 \mathrm{mg} / \mathrm{l}$. Larger aliquots were used to inoculate the centre of membrane filters $(0.45 \mu \mathrm{m}$ pore size, $47 \mathrm{~mm}$ diameter; Millipore, Harrow, Middlesex, England) placed on the surface of both agar media as described by Holdeman et al. ${ }^{10}$ The inoculum was confined within a sterile nylon washer (39 $\mathrm{mm}$ in diameter) sealed to the filter with sterile vaspar. A $1 \mathrm{ml}$ aliquot of the faecal suspension was inoculated into $200 \mathrm{ml}$ brain heart infusion broth with spectinomycin and polymyxin (BHF-SP) as an enrichment culture.

We incubated plates and broth within the anaerobic chamber at $36^{\circ} \mathrm{C}$ and high humidity. Filters were removed from plates after five days. All plates were examined for growth every day for three weeks. Wet smears of the surface of agars were checked by dark field and phase contrast microscopy. A haemolysis pattern on blood agar was noted, and obligate anaerobiosis of the isolate was confirmed if aerobic and microaerophilic subcultures did not grow.

\section{ELECTRON MICROSCOPY IDENTIFICATION OF ORGANISMS}

Suspensions of the organisms obtained from culture were drawn on to a membrane filter $(0.22 \mu \mathrm{m})$. The filters were fixed in buffered glutaraldehyde $(\mathrm{pH} 7 \cdot 2)$ and subjected to scanning electron microscopy. Blocks of agar with surface colonies were fixed similarly and subjected to transmission electron microscopy.

\section{Results}

The table shows the results of electron microscopy. Five of the eight homosexual men studied, including the three who had lower gastrointestinal tract systems, had spirochaetal infestation of the rectum. At the time of biopsy, Gram stain and culture of rectal smears from all eight patients gave negative results.

Three of the five patients with spirochaetosis showed a high degree of mucosal attachment of spirochaetes. The mean number of spirochaetes attached to each epithelial cell varied from 7.8 to 40.7 (mean of eight adjacent cell counts). In the two other patients, lower degrees of cellular attachment were found (mean counts of 3.2 and 3.6 organisms). Figure 1 shows the mean number of microvilli per cell found in biopsy specimens from all the patients studied. The number of epithelial microvilli seen in the homosexual men (regardless of the degree of spirochaetosis) was considerably less than in heterosexual men of comparable age. Homosexual men with spirochaetal 
TABLE Numbers of microvilli and spirochaetes on rectal mucosal cell surfaces (mean of counts for eight adjacent cells)

\begin{tabular}{|c|c|c|c|c|c|}
\hline \multirow[b]{2}{*}{ Case No } & \multirow{2}{*}{$\begin{array}{l}\text { Symptons of } \\
\text { proctits }\end{array}$} & \multirow{2}{*}{$\begin{array}{l}\text { Culture of } \\
\text { spirochaetes }\end{array}$} & \multirow{2}{*}{$\begin{array}{l}\text { Degree of } \\
\text { spirochaetal } \\
\text { attachment }\end{array}$} & \multicolumn{2}{|c|}{ Mean No (per mucosal cell) of: } \\
\hline & & & & Microvilli & Spirochaetes \\
\hline $\begin{array}{l}\text { Homosexuals: } \\
1 \\
2 \\
3 \\
4 \\
5 \\
6 \\
7 \\
8\end{array}$ & $\begin{array}{l}\text { Absent } \\
\text { Present } \\
\text { Present } \\
\text { Present } \\
\text { Absent } \\
\text { Absent } \\
\text { Absent } \\
\text { Absent }\end{array}$ & $\begin{array}{l}\text { Positive } \\
\text { Positive } \\
\text { Positive } \\
\text { Positive } \\
\text { Positive } \\
\text { Negative } \\
\text { Negative } \\
\text { Negative }\end{array}$ & $\begin{array}{l}\text { High } \\
\text { High } \\
\text { High } \\
\text { Low } \\
\text { Low } \\
\text { Nil } \\
\text { Nil } \\
\text { Nil }\end{array}$ & $\begin{array}{r}4 \cdot 0 \\
8 \cdot 2 \\
19 \cdot 1 \\
23 \cdot 1 \\
18 \cdot 3 \\
28 \cdot 3 \\
13 \cdot 2 \\
23 \cdot 4\end{array}$ & $\begin{array}{r}30.0 \\
40.7 \\
7.8 \\
3.6 \\
3.2\end{array}$ \\
\hline $\begin{array}{l}\text { Heterosexuals: } \\
\quad 1 \\
2 \\
3 \\
4 \\
5\end{array}$ & $\begin{array}{l}\text { Absent } \\
\text { Absent } \\
\text { Absent } \\
\text { Absent } \\
\text { Absent }\end{array}$ & $\begin{array}{l}\text { Negative } \\
\text { Negative } \\
\text { Negative } \\
\text { Negative } \\
\text { Negative }\end{array}$ & $\begin{array}{l}\text { Nil } \\
\text { Nil } \\
\text { Nil } \\
\text { Nil } \\
\text { Nil }\end{array}$ & $\begin{array}{l}46 \cdot 2 \\
45 \cdot 9 \\
41 \cdot 1 \\
46 \cdot 4 \\
51 \cdot 6\end{array}$ & \\
\hline
\end{tabular}

infestation showed a further, though less pronounced, decrease in the number of microvilli compared with non-infested homosexuals. In the assessment of variation between the observers counting microvilli, close agreement was seen $(r=0.87)$.

\section{CHARACTERISTICS OF THE ORGANISMS}

\section{Light microscopy}

We examined live spirochaetes by phase contrast microscopy or with the dark field technique. The organisms were short, thin, and flexible and showed a serpentine type of motility.

\section{Electron microscopy}

Over large regions of the rectal mucosa, spirochaetes could be seen between and parallel to the microvilli of the luminal cells (figs 2 and 3). Intracellular spirochaetes were not detectable. Where mucosal attachment was found, the spirochaetes were attached end on to the luminal cell membranes, and the attachment site was characterised by a small pit between the tip of the organism and the cell membrane.

\section{Cultured organisms}

The ultrastructure of the organisms cultured from the stool of affected patients was identical to that of the organisms seen in rectal biopsy specimens (fig 4). They grew only under strictly anaerobic conditions. The spirochaetes were enveloped in a double layered membrane of asymmetric electron density. Ribosomes and nuclear regions were seen in the interior of the cells, and four to 10 flagellas could be found in the periplasmic space (fig 5), probably indicating four to five flagellas arising from each end of the cell and interdigitating. On the basis of these morphological characteristics we identified the organisms as being from the genus Treponema of the family Spirochaetae. They differ from Brachyspira aalborgi in three respects: ${ }^{2}$ they are less nutritionally fastidious, they grow faster (three to five days on subculture), and they can be cultivated at both $37^{\circ} \mathrm{C}$ and $42^{\circ} \mathrm{C}^{2}$

\section{Discussion}

The large anaerobic treponemal organisms isolated from our patients closely resembled the spirochaetes previously observed in human rectal epithelium and those cultivated from both human stool and rectal biopsy material by other workers. By normal criteria they would be classified as Treponema spp as there were cultural differences that distinguish them from Brachyspira aalborgi, which itself differs in several

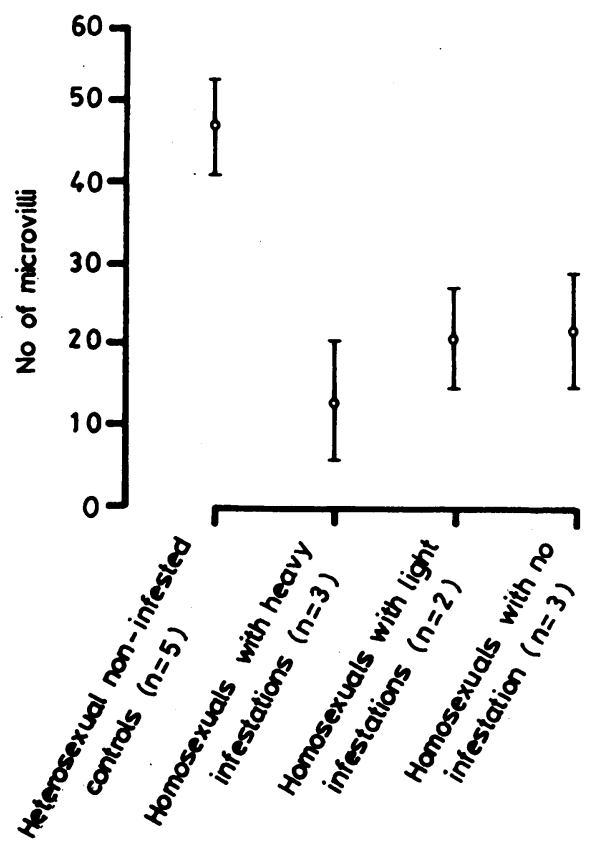

FIG 1 Number of microvilli per rectal mucosal cell in biopsy specimens from 13 men (mean for eight adjacent cells, bars represent $S D)$. 


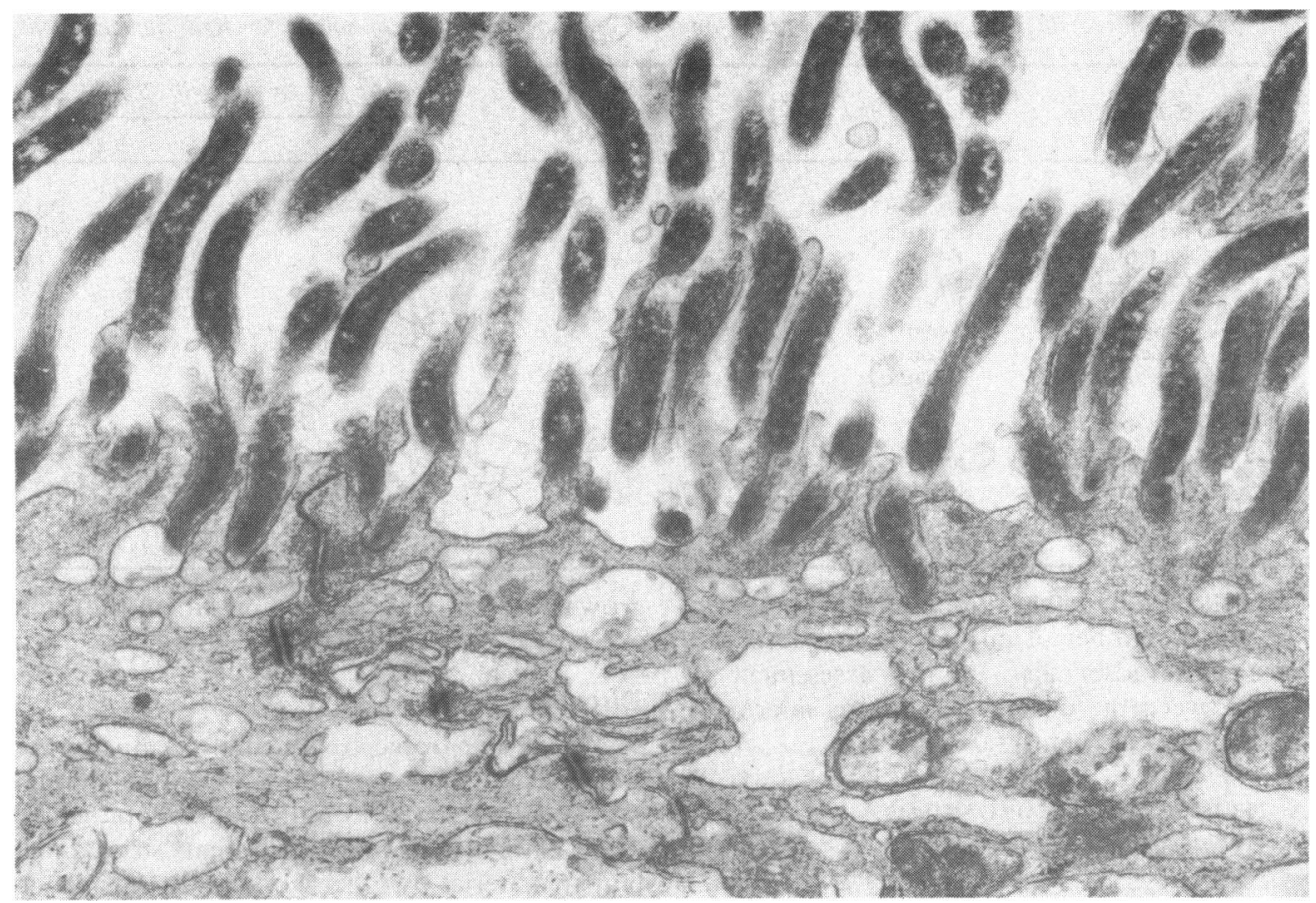

FIG 2 Transmission electron micrograph of infested mucosal surface showing attachment of spirochaetes and reduction in number of microvilli. Toluidine blue $\times 23680$ (original magnification).

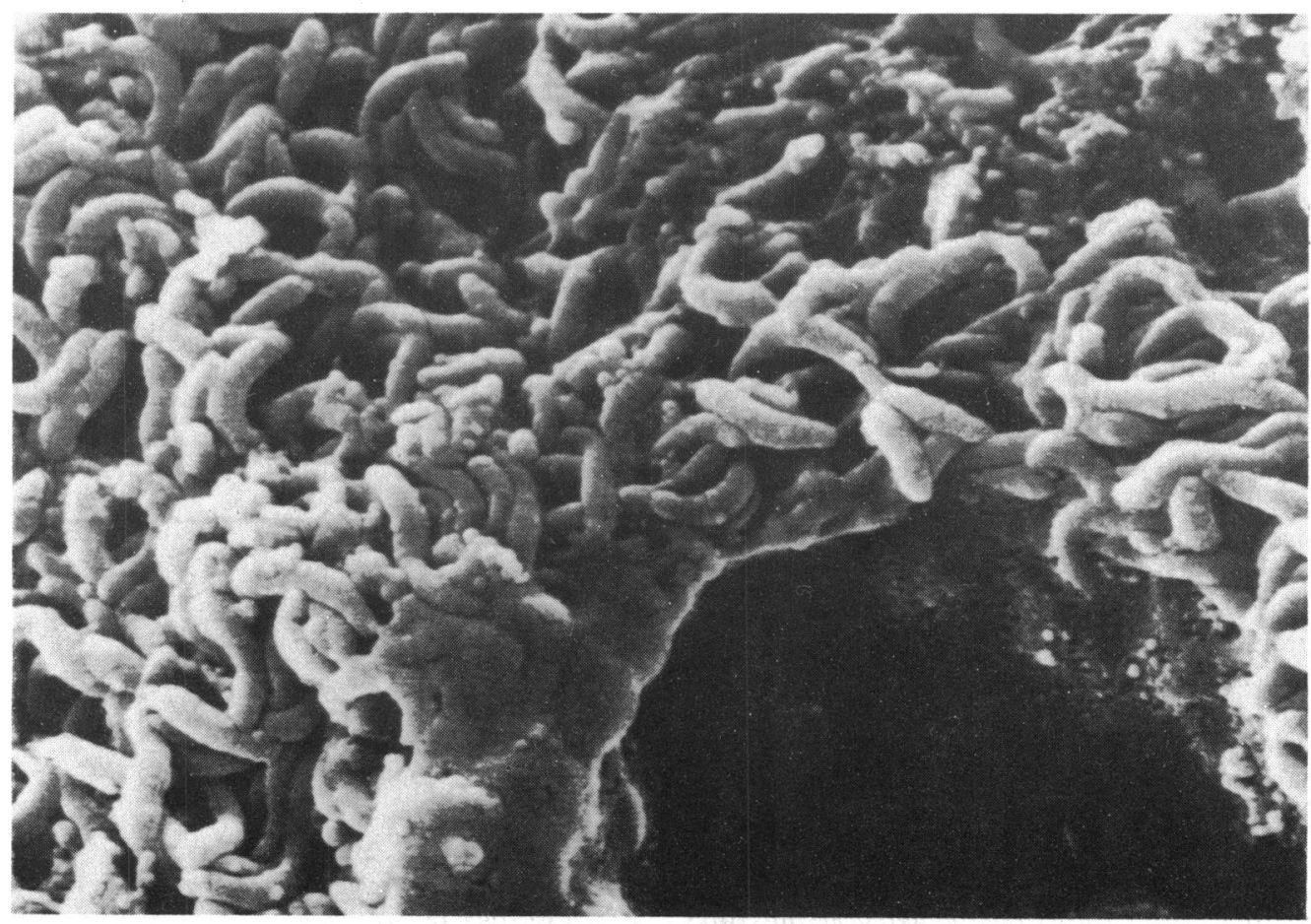

FIG 3 Scanning electron micrograph of infested mucosal surface. $\times 17880$ (original magnification). 


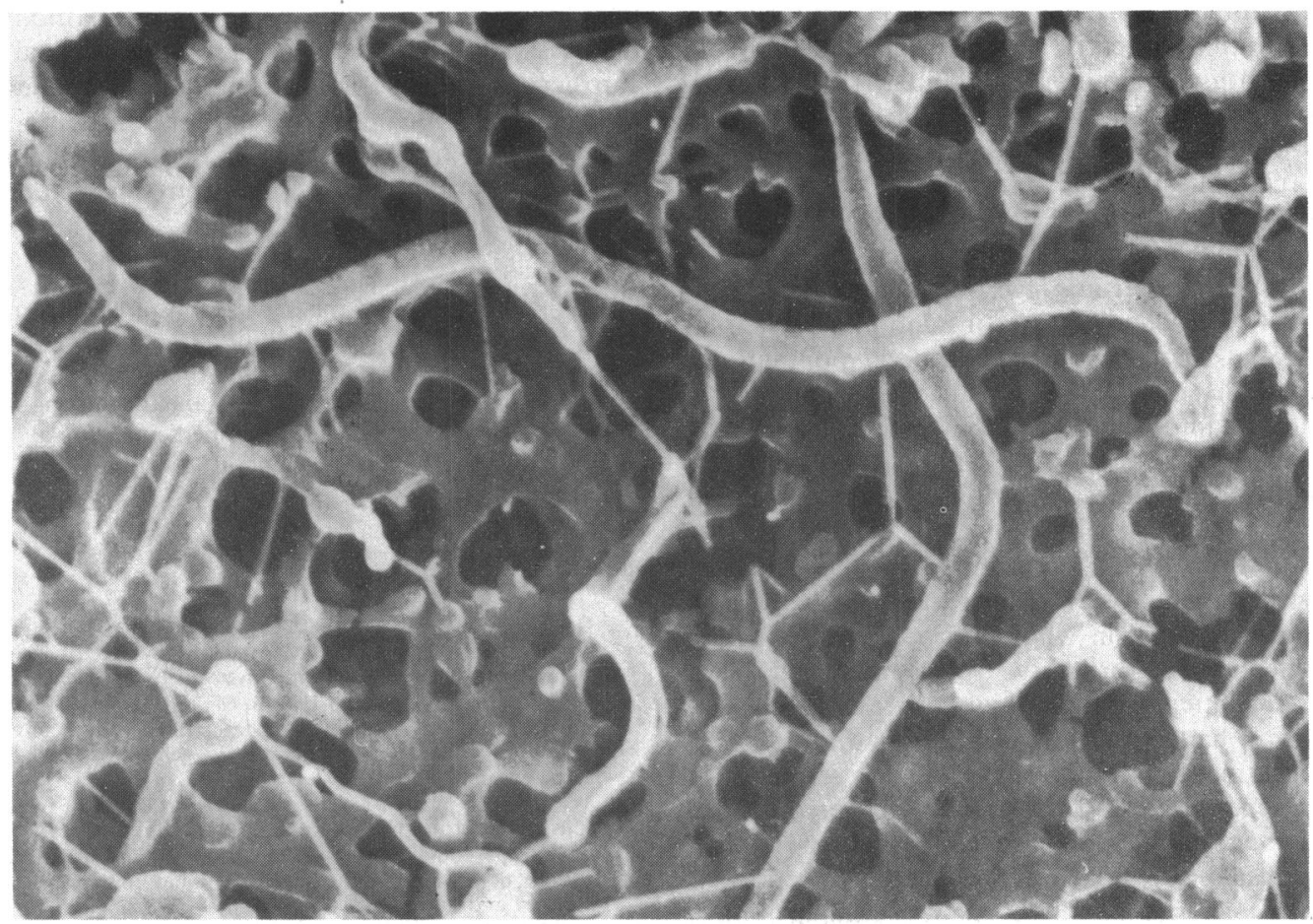

FIG 4 Scanning electron micrograph of isolated spirochaetes on Millipore membrane filter. $\times 17880$ (original magnification).

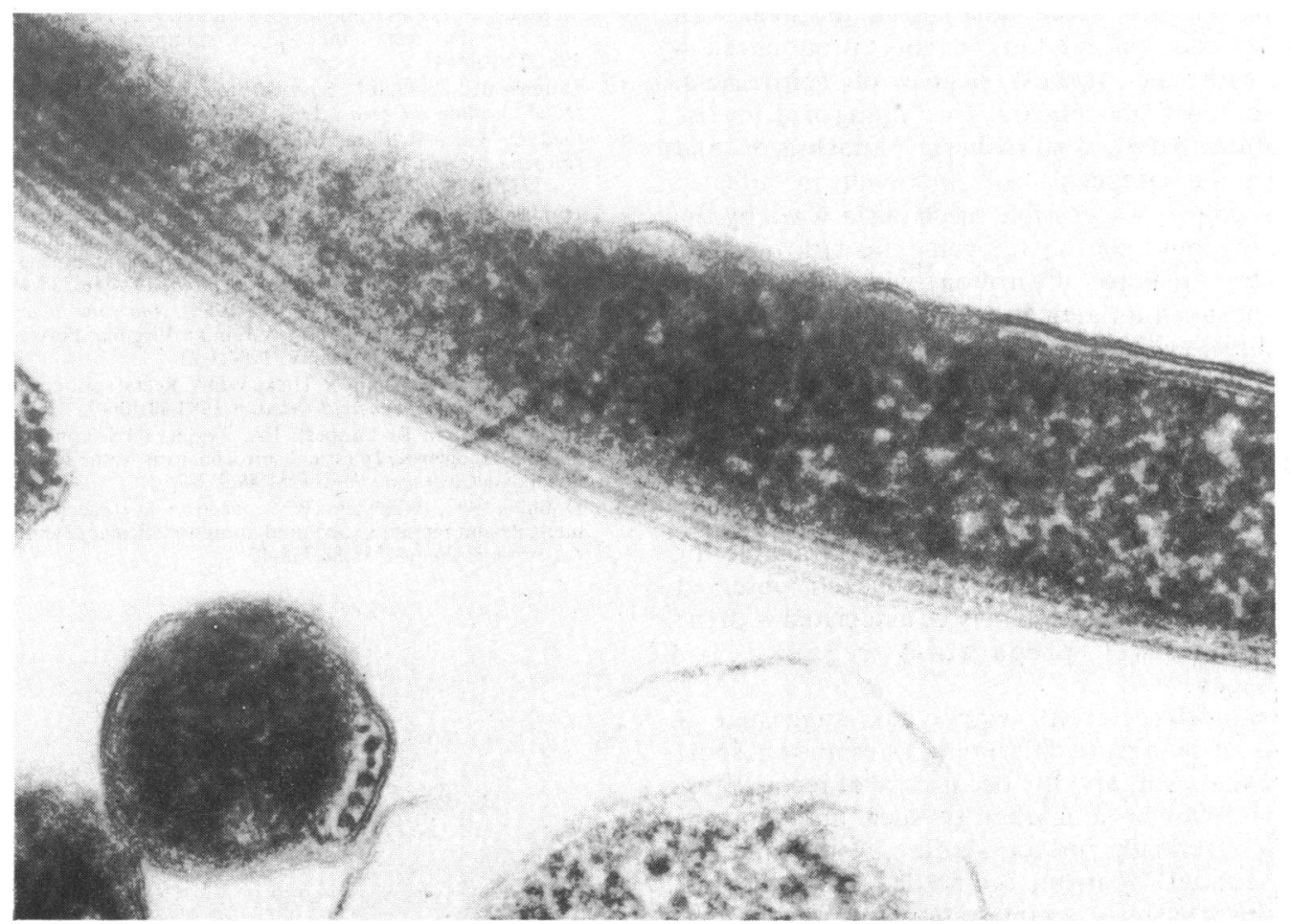

FIG 5 Transmission electron micrograph of isolated spirochaetes on agar blocks. Toluidine blue $\times 26250$ (original magnification). 
respects from the spirochaetes isolated from the lower gastrointestinal tract of several animals and from those responsible for swine dysentery (T hyodysenteriae). The spirochaetes phenotypically resembled non-pathogenic commensal treponemes isolated from the porcine intestine.

Though the number of patients was small and the group was highly selected, our results agree with those of McMillan and Lee in suggesting that the prevalence of rectal spirochaetes is considerably higher in homosexual men than in the general population. ${ }^{6}$ Considerable disagreement still exists about the pathological importance of such infestation. It is fairly well established that in heterosexual hospital populations spirochaetosis is of little importance ${ }^{1}$ and is only very occasionally associated with symptoms. The situation would appear to be different in homosexual men, however, and symptomatic patients have been reported in whom spirochaetosis was the only detectable abnormality. ${ }^{811}$ It is noteworthy that both our patients with a high degree of mucosal association had symptoms of proctitis that subsided when treatment with metronidazole was started.

The generalised loss of microvilli noted in the reactal mucosa of homosexual men compared with heterosexuals of similar ages (not hitherto reported) may have occurred as a direct result of trauma or have been related to recurrent infection at this site. The loss of microvilli was accentuated in all the men with spirochaetosis, and the loss was most pronounced in those with the greatest degree of spirochaetal association with the mucosa. The finding of an inverse correlation between spirochaetal attachment and numbers of epithelial cell microvilli in affected patients suggests a possible mechanism whereby the organisms could exert a pathogenic effect (through the blockade of passive absorption) without eliciting a potent host cell inflammatory response.

No direct evidence exists of uniform infestation of the colon by spirochaetes in affected patients; but previous reports have described spirochaetosis of the appendix. ${ }^{5} 12$ Though we have exmained many biopsy specimens taken at colonoscopy, spirochaetosis has never been observed in the patients from whom they were taken and material has not been available for electron microscopic studies. This lack of observed spirochaetosis of the colon may be associated with the thorough bowel preparation required for colonoscopy.

Considerable recent work has suggested a generalised deficiency of the immune response in some homosexual men, and the occurrence of rectal spirochaetosis may be a marker of such immunocompromise, ${ }^{13}$ though further studies of the immune response in such patients are needed. None the less, rectal spirochaetosis, an infestation that was thought to be largely incidental in the population as a whole, may be associated with the clinical and pathological features of a disease process in some homosexual men. Further controlled studies are required to assess the natural history of this condition, and its response to antibiotic treatment, as well as to elucidate the complex relation between the spirochaete and the human immune response.

We thank the staff of the department of electron microscopy for their skilled technical help in preparing transmission grids and scanning photomicrographs. We also thank Mr A Stirling (Health Adviser) and the nursing staff of the department of genitourinary medicine, Royal South Hants and Southampton General Hospitals, for their generous help.

\section{References}

1. Neilsen RH, Orholm M, Pederson JO, Hovind-Hougen $\mathrm{K}$, Teglbjaerg PS, Thaysen EH. Colorectal spirochaetosis: clinical significance of the infestation. Gastroenterology 1983;85:62-7.

2. Hovind-Hougen $K$, Anderson $A B$, Neilsen RH, et al. Intestinal spirochaetosis: morphological characterization and culivation of the spirochaete Brachyspira aalborgi gen nov, sp nov. J Clin Microbiol 1982;16:1127-36.

3. Tomkins IS, Waugh MA, Cooke EM. Isolation of intestinal spirochaetes from homosexuals. J Clin Pathol 1981;34:1385-7.

4. Takeuchi A, Jervis HR, Nakazawatt H, Robinson DM. Spiral shaped organisms on the surface colonic epithelium of the monkey and man. Am J Clin Nutr 1974;27:1287-96.

5. Lee FD, Kraszewski A, Gordon J, Howie JGR, McSeveney I, Harland WA. Intestinal spirochaetosis. Gut 1971;12:126.330.

6. McMillan A, Lee FD. Sigmoidoscopic and microscopic appearance of the rectal mucosa in homosexual men. Gut 1981;22:1035-41.

7. Douglas JC, Crucioli V. Spirochaetosis: a remediable cause of rectal bleeding. $\mathrm{Br}$ Med J 1981;283:1362.

8. Gad A, Willen R, Furgard K, Fors B. Hradsky M. Intestinal spirochaetosis as a cause of long standing diarrhoea. Ups JMed Sci 1977;82:49-54.

9. Hudson MJ, Hill MJ, Elliott PR, Berghouse LM, Burnham WR, Jones JEL. The microbial flora of the rectal mucosa and faeces of patients with Crohn's disease before and during antimicrobial chemotherapy. J Med Microbiol 1984;18:335-45.

10. Holdeman LV, Cato EP, Moore WEC. Anaerobe laboratory manual. 4th ed. Blacksburg, Virginia: Virginia Polytechnic Institute and State University, 1984:1-23.

11. Cotton DWK, Kirkham N, Hicks WDA. Rectal spirochaetosis. British Journal of Venereal Diseases 1984;60:106-9.

12. Henrick-Nielsen R, Lunbeck FA, Teglberg PS, Ginnerup P, Hovind-Hougen K. Intestinal spirochaetosis of the vermiform appendix. Gastroenteology 1985;88:971-7.

13. Dobbins WO, Weinstein WM. Electron microscopy of the intestine and rectum in acquired immunodeficiency syndrome. Gastronenterology 1985;88:738-49. 